\title{
Editorial
}

\section{5 años de la Ley de Prevención de Riesgos Laborales. Una buena base para afrontar un futuro más exigente}

\section{5 years after the promulgation of the Act on Prevention of Occupational Risks. A good foundation for facing a more demanding future}

\author{
Francisco Javier Pinilla-García' \\ 'Director, Instituto Nacional de Seguridad y Salud en el Trabajo, Madrid, España.
}

Recibido: 13-12-2020

Aceptado: 17-12-2020

\section{Correspondencia}

Francisco Javier Pinilla García

javier.pinilla@insst.mites.gob.es

En noviembre de 2020 se han cumplido 25 años de la promulgación de la Ley de Prevención de Riesgos Laborales (LPRL). Sin duda ello constituyó un hecho trascendental para la historia de la prevención de los riesgos laborales y la protección de la salud de los trabajadores y trabajadoras en España. Con ello se iniciaba el proceso de modernización del marco jurídico de la prevención en España.

La LPRL es fruto de la trasposición a la normativa española de la Directiva Comunitaria 89/391/CEE; dicha Directiva imponía de plazo para su trasposición al ordenamiento jurídico de los Estados miembros hasta finales de 1992, plazo que, no obstante, en España se sobrepasó ampliamente. Este retraso fue una clara muestra de la dificultad que esta tarea representó para el legislador español. Mientras la mayor parte de nuestros socios comunitarios decidieron hacer limitadas modificaciones en sus regulaciones nacionales a fin de adecuarse a los requisitos comunes que imponía la Directiva, en el caso de España se optó por precipitar una transformación en profundidad, ante la evidente obsolescencia técnica y social de la Ordenanza General de Seguridad e Higiene en el Trabajo (OGSHT) de 1971, que en ese momento constituía la norma básica en la materia.

Desde el punto de vista técnico el enfoque, a menudo tan detallado, de algunas de las disposiciones de esta norma impedía la necesaria flexibilidad y adaptabilidad a los cambios tecnológicos que se habían ido produciendo en multitud de sectores productivos en los casi 25 años anteriores. Desde el punto de vista social, la Ordenanza y el Reglamento de los Comités de Seguridad e Higiene en el Trabajo que la acompañaba habían sido pronto superadas por el modelo de relaciones laborales y, en particular, por los requisitos de participación de los trabajadores plasmado en el Estatuto de los Trabajadores de 1980. De esta forma, se imponía una revisión en profundidad que modernizara y se alineara con los criterios internacionales y europeos que se habían ido plasmando tanto en convenios de la Organización Internacional del Trabajo (OIT), en particular el número 155 sobre seguridad y salud de los trabajadores y el 161 sobre los servicios de salud en el trabajo, como en las directivas comunitarias, la 89/391/CEE, denominada "la marco" y hasta siete más que fueron desarrollándola de forma casi inmediata. Además, esta trasposición debía ser coherente e inte-

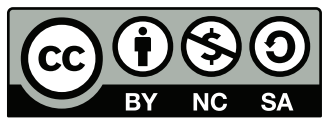

https://creativecommons.org/licenses/by-nc-sa/4.0/ 
grarse en el conjunto de la regulación laboral y con las instituciones laborales existentes. Ello explica lo largo y azaroso que fue el proceso de diálogo social hasta su definitiva promulgación, cerrando así un período de casi 25 años en los que la prevención en los lugares de trabajo estuvo regulada por la citada OGSHT.

Si bien la promulgación de un texto normativo que nos homologaba a los principios y prácticas preventivas más avanzadas y comunes entre los principales países europeos auguraba una sustancial mejora de la seguridad y salud de los trabajadores, sin embargo, en un primer momento, los datos estadísticos, en particular de siniestralidad, no acompañaron las enormes expectativas creadas por la definitiva aplicación de la Ley a partir de los primeros meses de 1996. Y es que esta norma constituía tan solo el principio de un proceso de cambio al que le faltaban entonces otros fundamentales elementos. El primero fue solventado con la publicación del Reglamento de los Servicios de Prevención. En él se estableció el modelo de asesoramiento técnico preventivo del que las empresas podrían disponer en función de sus características y necesidades. Pero si bien el andamiaje normativo se fue pronto completando y ajustando, lo cierto es que el objetivo más trascendente y señalado de forma explícita en el texto legal, esto es, ese cambio cultural que facilite la incorporación de la sensibilidad preventiva en las tareas cotidianas en el seno de las empresas, parecía aún lejos de alcanzarse. La integración de la prevención continúa siendo hoy uno de los aspectos que suelen ser señalados como de necesaria mejora. Es cierto que ya muchas empresas ven cómo ese tipo de aproximación en la gestión de la prevención constituye una forma exitosa, pues fomenta sinergias entre los distintos objetivos empresariales. No obstante, muchas otras, en particular las más pequeñas, tienen dificultades especiales para ello, sobre todo, a causa de la falta de recursos preventivos internos y del asesoramiento que pueden recibir desde fuera de la empresa que puedan integrar en sus tareas específicas de producción y servicio.

Los aniversarios constituyen una buena ocasión para hacer balances y marcar etapas. Los veinticinco años que han transcurrido desde la promulgación de la Ley 31/1995 merecen celebrar los innegables logros alcanzados en el camino recorrido, pero, aún más, requieren un balance riguroso de qué debemos mejorar para afrontar los retos que se nos imponen. En estos años se han producido cambios trascendentales en la tecnología empleada en los lugares de trabajo y en la forma en que las empresas organizan su actividad y gestiona su relación con los trabajadores que emplean. Ello determina a su vez los riesgos a los que se exponen los trabajadores y trabajadoras. Las fuentes de estos riesgos son variadas y cada día se tornan más complejas. Van desde los riesgos de seguridad tradicionales asociados a maquinas a los más actuales derivados de la interacción con robots industriales, tiene que ver con exposiciones ambientales a contaminantes bien conocidos como puede ser el amianto, la sílice, o con otros como los que ocasionan cáncer o la exposición a nanopartículas. Afectan al componente físico de la persona, provocando lesiones musculoesqueléticas que limitan la calidad de vida de los trabajadores y trabajadoras y los abocan a la exclusión laboral y social, pero también afectan a su mente, provocando variadas patologías y sufrimientos mentales.

Para enfrentar todas estas amenazas que acechan al mundo del trabajo no hay más antídoto que más y mejor suma de conocimiento experto. Para crear este conocimiento se necesita investigar y experimentar y ello requiere de instalaciones, laboratorios con personal capaz de facilitar evaluaciones de calidad, de interpretar y proponer regulaciones claras y eficaces, de ensayar procedimientos y métodos para suministrar, a los especialistas en las empresas, nuevas y más sencillas metodologías preventivas. En definitiva, ello requiere de un fortalecimiento de las instituciones científicas y técnicas que atienden a la seguridad y la salud de la población trabajadora y una alianza de objetivos compartidos como la que forma el Instituto Nacional de Seguridad y Salud en el Trabajo y el Instituto de Salud Carlos III, que se proyecta en distintos campos como la incorporación de la Seguridad y Salud en la agenta de la Acción Estratégica en Salud, la formación especializada en Salud Pública y Medicina Preventiva mediante la colaboración con la Escuela Nacional de Sanidad y, de una forma especial, la formación especializada en Medicina y Enfermería del Trabajo a través de la colaboración con una institución hermana como es la Escuela Nacional de Medicina del Trabajo. 
En estos tiempos de pandemia una de las enseñanzas que nos deja esta trágica experiencia es el del valor del conocimiento técnico y científico y la necesidad de generar evidencias para abordar de forma eficiente situaciones críticas. Debemos enfrentar un futuro más incierto y amenazador de lo que nunca sospechamos y, para ello, hay que potenciar las herramientas que, como humanos, nos han hecho progresar, esto es, combinar ingenio y cooperación. Esto mismo es lo que se requiere en los lugares de trabajo para afrontar los numerosos y variados riesgos laborales que amenazan a la seguridad y la salud de la población trabajadora. Hemos aprendido que el progreso de un tejido económico se garantiza uniendo salud y talento en la gestión de las organizaciones.

La Ley de Prevención de Riesgos Laborales supuso para el mundo laboral español un innegable salto de modernidad. Hoy, tras 25 años, su adaptación a las profundas transformaciones tecnológicas, organizativas y de los modos de gestión en las empresas aconseja no demorar su necesaria reforma, a fin de seguir siendo útil para proteger la seguridad y la salud de trabajadores y trabajadoras.

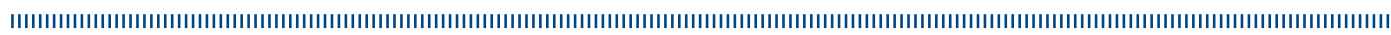

